\title{
HIV testing for pregnant women: A rights-based analysis of national policies
}

\author{
Elizabeth J. King ${ }^{\mathrm{a},{ }^{\star},}$, Suzanne Maman ${ }^{\mathrm{b}}$, Sarah C. Wyckoff ${ }^{\mathrm{b}}$, Matthew W. Pierce ${ }^{\mathrm{c}}$, and Allison \\ K. Groves ${ }^{b}$ \\ aYale University School of Public Health, New Haven, CT, USA \\ bGillings School of Global Public Health, University of North Carolina at Chapel Hill, Chapel Hill, \\ NC, USA \\ 'Health Law \& Justice Program at American University, Washington College of Law, Washington, \\ DC, USA
}

\begin{abstract}
Ethical and human rights concerns have been expressed regarding the global shift in policies on HIV testing of pregnant women. The main purpose of this research was to conduct a policy analysis using a human rights-based approach of national policies for HIV testing of pregnant women. We collected HIV testing policies from 19 countries including: Cambodia, China, Guyana, Haiti, India, Jamaica, Kenya, Moldova, Papua New Guinea, Russian Federation, South Africa, Sudan, Swaziland, Tanzania, Ukraine, United States, Uzbekistan, Zambia and Zimbabwe. We analysed the HIV testing policies using a standardised framework that focused on government obligations to respect, protect and fulfil. Our results highlight the need for more attention to issues of pregnant women's autonomy in consenting to HIV testing, confidentiality in antenatal care settings and provision of counselling and care services. We conclude with a discussion about potential implications of the current testing policies and provide recommendations for ways that HIV testing policies can more effectively uphold the human rights of pregnant women.
\end{abstract}

\section{Keywords}

HIV testing; pregnant women; human rights; consent; HIV counselling

\section{Introduction}

In light of improved methods for the prevention of mother-to-child transmission (PMTCT) of HIV since the early 2000s, there has been an increasing focus on the uptake of HIV testing among pregnant women. In 2006, the Centers for Disease Control and Prevention (CDC) released new guidelines on HIV counselling and testing in the United States (CDC 2006). In 2007, the World Health Organization (WHO) and the Joint United Nations Programme on HIV and AIDS (UNAIDS) released a revised HIV testing guidance

\footnotetext{
(c) 2013 Taylor \& Francis

*Corresponding author.elizabeth.king@yale.edu.
} 
document (WHO and UNAIDS 2007). In recent years, some countries have adopted new HIV testing guidelines and policies for pregnant women. Human rights concerns have been voiced in regard to the shift in HIV testing and counselling guidelines to a streamlined approach, in which the pretest counselling is simplified and the testing process shortened, especially for pregnant women (Gruskin et al. 2008). However, to our knowledge, there has not been an examination of national policies on HIV testing of pregnant women.

Policies directed toward pregnant women raise specific issues given the potentially vulnerable situation that many of the world's women face. It is important to consider that, in many settings, healthcare providers are trained professionals and part of their training is to assume a role of authority in matters related to health. Thus, patients are socialised not to ask questions of providers because this may come across as doubting their authority. There is likely to be great social distance, such as class, language and power dynamics, between women and healthcare providers given gender norms in many places that marginalise women (Gruskin et al. 2008). This means that women may be less able to speak out and decline testing when it is integrated into medical services. Research has shown that women may feel that they have to test in order to receive services (Pool et al. 2001). Additionally, pregnant women who have not tested for HIV may be given a rapid test during labor. This raises ethical concerns over the likelihood a woman can receive proper counselling, if she is able to give informed consent during this time or whether she would be able to cope with a new HIV diagnosis (Avert 2012). This is where the importance of a rights-based approach to HIV testing becomes crucial to ensuring that HIV testing policies have considered the potential risks and benefits to the populations being targeted.

There may be several reasons why targeting women with efforts to increase HIV testing carries potential risks. There are often specific reasons that women do not want to be tested for HIV, for example: fear of negative reactions from partners (Campbell and Bernhardt 2003, Jones 2004), low perception of risk (Yin et al. 2003, de Paoli et al. 2004) and fear of stigma (Fernandez et al. 2000, Peltzer et al. 2007). The studies that examine fear of negative social consequences are of particular importance in furthering our understanding of the complexity of factors affecting testing uptake. Women are more likely than men to be targeted for HIV testing given that they have more contact with healthcare facilities (Csete et al. 2004, Gruskin et al. 2008). There is evidence from a variety of international settings that indicates some women fear stigma, discrimination, abandonment, violence, expulsion from the home and partner accusations of infidelity when they test for HIV (Pool et al. 2001, Maman et al. 2002). Additional research has shown the realities of women's disclosure of HIV tests to include abandonment, loss of economic support, experienced stigma, blame and violence (Gielen et al. 2000, Maman et al. 2002). Research conducted in sub-Saharan Africa and Southeast Asia found that $3.5 \%$ to $14.6 \%$ of HIV-positive women reported a violent reaction from their partner following disclosure (Medley et al. 2004). Research from Russia demonstrated that HIV-positive pregnant women faced stigmatisation from healthcare providers and received pressure to abort (Burns 2007). Research among women in the United States showed that $4 \%$ reported physical abuse following a disclosure event and $45 \%$ reported experiencing emotional, physical or sexual abuse at some time after their diagnosis (Gielen et al. 2000). Because pregnant women are not necessarily seeking HIV testing when 
they attend an antenatal clinic, they may be unprepared to handle positive results when confronted with the provider-initiated models of testing in their healthcare facility (Galletly et al. 2008).

Voluntary counselling and testing has been ethically guided by the three cornerstones of consent, confidentiality and counselling. Commonly referred to as the three C's of HIV testing, these cornerstones were, in part, identified to protect individuals from potentially adverse outcomes associated with learning one's HIV status, such as stigma and discrimination (UNAIDS/WHO 2004). The three Cs help to ensure that individual autonomy and essential human rights are protected in public health efforts to increase HIV testing. 'HIV exceptionalism', meaning that HIV policies require approaches different from other disease control measures, came into public health discourse largely because of concerns over human rights violations (DeCock 1998). Informed consent, confidentiality and patientprovider communication were believed to help uphold human rights; counselling was believed to be an important part of the HIV testing process (DeCock 1998). Recent desires to expand testing because of advances in treatment options and the belief that some of the earlier stigma has lessened have led to a reconsideration of the notion that HIV is exceptional from other conditions that are screened for in healthcare settings (DeCock 1998). Consistent with other human rights scholars and public health researchers, we argue that potential social risks women could experience after HIV testing make HIV a disease that is different from other conditions that are screened for in healthcare settings (Csete $\mathrm{et}$ al. 2004, Rennie and Behets 2006, Bennett 2007, Gruskin et al. 2008). Therefore, the three Cs and a rights-based approach should remain important aspects guiding the development of HIV testing policies. The main purpose of this research was to conduct a policy analysis using a human rights-based approach of national policies for HIV testing of pregnant women.

\section{Methods}

We collected HIV testing policies ${ }^{1}$ from 19 countries including: Cambodia, China, Guyana, Haiti, India, Jamaica, Kenya, Moldova, Papua New Guinea, Russian Federation, South Africa, Sudan, Swaziland, Tanzania, Ukraine, United States, Uzbekistan, Zambia and Zimbabwe. Our primary aim in selecting countries was to have global representation. The secondary selection criteria within global regions were to focus on low- and middle-income countries with higher HIV prevalence among the general population or with concentrated epidemics among vulnerable populations. Between January and May 2008, we contacted representatives in each of the countries identified through UNAIDS and UNICEF representatives listed on the websites, Ministries of Health, National AIDS organisations, $\mathrm{CDC}$ in-country representatives and through existing professional contacts.

Most policies were available in English. We reviewed policies from five countries in their original language (Haiti, Moldova, Russia, Ukraine and Uzbekistan), and we had one policy document translated into English for inclusion in our review (China). Nine of the policies were specific to HIV testing of pregnant women. For the remaining 10 documents in our

\footnotetext{
${ }^{1}$ Note: We use the term 'policy' in this paper inclusively for national laws, policies or guidelines on HIV testing of pregnant women.
} 
sample, we reviewed general HIV testing policies, and subsequently focused our analysis on the sections that specifically addressed testing of pregnant women. All of the countries reviewed had released new or revised policies between 2003 and 2008. Table 1 provides a description of the testing policies we included in the analysis.

We developed a framework for analysing the extent to which national policies were protective of human rights. This framework included the cornerstones of HIV testing and counselling designed to uphold human rights and also key criteria to assess governments' commitment to protect pregnant women's health and well-being. To create the framework, we used information from the United Nations Development Programme's (UNDP) tool for analysing governments' obligations according to international human rights law (UNDP 2008). UNDP outlined the need for a human rights analysis of HIV policies and programmes to ensure that they are consistent with international human rights law, to understand who is controlling resources and to examine the impact these policies and programmes have on individual lives. UNDP provided a tool for examining governments' obligations to protect the right to health, which included the following three components: obligation to respect, obligation to protect and obligation to fulfil. The obligation to respect is defined as the obligation of states not to interfere with or violate human rights through government action (OHCHR 2011). We focused on making sure the testing policies do not violate the right of a person to decline an HIV test (consent) and confidentiality. The obligation to protect is defined as the obligation of states to protect individuals from human rights violations by non-state actors (OHCHR 2011). We focused on states protecting women from potential adverse consequences as a result of HIV testing or an HIV diagnosis, including violence. The obligation to fulfil is defined as the obligation of states to take measures to create an environment where people can enjoy their rights (OHCHR 2011). We focused on the provision of adequate counselling services, on access to treatment and care for women who are diagnosed with HIV and on the implementation plans. We applied this framework to national policies, holding the states accountable to ensure that their national HIV testing laws and policies uphold these human rights obligations. We considered these three obligations with regard to HIV testing of pregnant women as outlined in Table 2.

After completing the individual reviews of each national policy, we developed matrices for cross-country comparison. We had the countries listed in rows and the components of the framework in columns. These matrices were organised according to the primary ideas from the framework as listed in Table 2. Based on the review of these national policies, we identified issues related to the rights of pregnant women within national HIV testing policies.

\section{Results}

We found different testing terminology used across our sample of HIV testing policies, including 'systematic', 'routine', 'recommended', 'provider-initiated' and 'opt-out'. The most common approach to testing policies for pregnant women was 'systematic' or 'routine', used in the policies of Moldova, Jamaica, South Africa, Swaziland, Lesotho, Zimbabwe, Kenya, Guyana, China and the United States. The policies for India, Tanzania, Cambodia and Papua New Guinea used the term 'provider-initiated testing and counselling' 
(PITC). The policies of Russia, Ukraine, Haiti and Tanzania called for 'recommended testing' of pregnant women attending antenatal care. Uzbekistan described its HIV testing policy for pregnant women as 'voluntary'. Additionally, the terminology of 'opt-out testing' was used to describe the policies of the United States, India, Guyana, Zambia, Sudan, Tanzania, Zimbabwe and Kenya. Countries whose policies were adopted earlier than 2007 more commonly referred to testing as 'routine' or 'systematic', while the laterreleased policies used the terms 'opt-out' and 'provider-initiated'. Despite the variance in terminology, all of the policies described a PITC model, meaning that providers commence the testing process. The major difference in testing policies across the countries was that, in some countries, the woman is explicitly offered an HIV test during pregnancy, and in other countries, the test is performed unless the woman clearly states she does not want the test.

We found limited reference to 'human rights', 'women's rights' and 'rights to' in the policies' text. General HIV testing policies tended to be more inclusive of human rights terminology and discussed these issues to a greater extent than was found in the policies specific to pregnant women. In the general testing policies, 'human rights' were mentioned by Uzbekistan, Zimbabwe, Tanzania, Papua New Guinea and India. Even when the reference to 'human rights' was made, the wording in some policies was vague. For example, Uzbekistan's policy did state that services should be 'carried out on a voluntary basis with doctor's confidentiality, anonymity, human relations, and upholding human rights'. However, there was no further clarification or elaboration on the statement 'upholding human rights', and there was no information on how these rights could be protected. 'Human rights' were not explicitly mentioned by the United States, Kenya or Moldova in their general HIV testing policies. Only Papua New Guinea's policy mentioned pregnant women specifically, by stating that they have a 'right to decline testing'. In the policies specific to testing pregnant women, 'human rights' were mentioned broadly in South Africa's policy and specifically in regard to HIV testing in the policies of Swaziland and Cambodia. In the pregnancy-specific policies, 'women's rights' were only directly mentioned in South Africa's policy. The South Africa policy stated that, 'Pregnant women and mothers have a right to HIV-related information, and to access treatment, management and care that will optimise their health and survival and prevent MTCT'. 'Human rights' or 'women's rights' were not explicitly mentioned in the policies of Russia, Ukraine, Sudan, Zambia, Jamaica, Haiti or China.

\section{Obligation to respect}

We reviewed policies for evidence that governments were meeting their obligation to respect; that is, evidence that the governments were not violating the rights of pregnant women through national HIV testing policies. We specifically looked at issues of consent and confidentiality in HIV testing policies.

Consent-A significant issue in regard to respecting human rights is that HIV testing is an informed choice and a person has the right to decline a test. All of the policies reviewed stated that HIV testing is voluntary; however, descriptions of consent requirements and protocols varied widely among the policies. We noted five ways in which the policies that we reviewed might have undermined the obligation to respect by preventing women from 
making an informed choice about testing. First, most of the policies were not clear about when consent should be obtained, that is, before or after pretest counselling. The policies of India, Cambodia and South Africa were the only policies that explicitly indicated that consent should be obtained after pretest counselling. The policies of China and Kenya provided little to no guidance on how providers should obtain consent. Guyana's policy only stated that pretest counselling and the consent process should both occur during the 'pretest session'. Second, we noted the lack of attention to advising women on potential negative outcomes or risks involved in being tested for HIV as part of the consent process. Only in the policies of Cambodia and India was it outlined that women should be counselled on potential risks of testing prior to consent. This omission was striking in policies such as those of Swaziland, Zambia and Papua New Guinea, which all provide fairly detailed accounts of the information that should be included in pretest counselling. Third, it was rare for national policies to dictate that consent be obtained in written form. Only two policies, those of Cambodia and South Africa, required that consent be in writing. Seven policies allowed consent to be verbal, and 10 countries did not specify how consent should be obtained. Fourth, we found that the policies did not outline what the consequences were if a pregnant women declined the HIV test. India had the only policy that explicitly stated that clients should be told that refusing to take the test will not affect their access to services. Fifth, we documented that two policies, those of the United States and Ukraine, indicated that newborns should be tested if the mother's HIV status is unknown. Neither policy addressed concern over or provided guidance on how to balance the rights of the mother with the rights of the infants.

Confidentiality -A second significant concern regarding the obligation to respect in HIV testing policies is to ensure that confidentiality is not violated. Confidentiality was addressed in all of the policies reviewed, except for China's policy. However, in many of the policies, the information included on confidentiality of testing results was broad. For example, Sudan's guidelines stated that there should be legal and ethical confidentiality around HIV testing, but no details were provided. The US recommendations stated that counsellors should provide test results in a confidential manner; however, specifics or clarification on what confidentiality entails were missing from the policy.

Some policies allowed for HIV test results to be shared in certain circumstances or to specific individuals. Nine policies (Zimbabwe, South Africa, Zambia, Haiti, Guyana, India, Russia, Ukraine and Moldova) permitted 'shared confidentiality', that is, notification of HIV serostatus from one healthcare worker to another. India's policy stated that counsellors should obtain consent before sharing a patient's status with another healthcare worker, but it also stated that healthcare workers are allowed to know the HIV status of their patients. In Kenya, Tanzania, Zimbabwe, Moldova and Guyana, confidentiality can be broken in cases where an HIV-positive person refuses to disclose his or her status to a sexual partner. In these cases, the provider is permitted within the law to disclose to the partner without the individual's consent.

Only one policy, that of Cambodia, included specific information on a woman's right to address a breach of confidentiality. As the consent form indicated, test results are kept confidential, and women have the 'right to file a complaint against anyone who discloses my 
HIV status without permission'. Cambodia's policy was an exception in our analysis. Most testing policies stated that, while test results should be treated confidentially, there were instances when a pregnant woman's test results could be shared, either among healthcare providers or with sexual partners.

\section{Obligation to protect}

We reviewed policies for evidence that governments were meeting their obligation to protect pregnant women's rights from violation by others. In order to assess whether there was adequate protection from the violation of women's rights, we considered the extent to which the policies addressed how to protect women from violence, stigma and other adverse consequences as a result of HIV testing or an HIV diagnosis. Across the policies, there was little documented concern for gender-based risks or potential negative outcomes to learning one's HIV status during pregnancy. There was no information in any of the pregnancyspecific policies regarding the protection of rights and welfare associated with any potential negative outcomes or consequences of HIV testing and learning one's status during pregnancy or at the time of delivery. In the general testing policies, women's rights were mentioned by Papua New Guinea, and women's vulnerability was recognised in Zimbabwe's policy. Zimbabwe's policy acknowledged that Zimbabwe is a patriarchal society where the role of males in the decision-making process is important for married women; and therefore, it is the government's responsibility to inform and educate men so that they can understand and support programmes like PMTCT. The pregnancy-specific policies of Ukraine and South Africa cited support for a woman's 'reproductive choice' if she tests positive or wants to plan future pregnancies after learning her HIV status. Guyana's policy was unique in that it included information on the need for efforts to reduce HIV/AIDS-related stigma and discrimination and to ensure a supportive legal and policy framework. Only in the South African policy was it stated that post-test counselling sessions should include information on the potential stigma women could experience because of their HIV-positive serostatus.

The policies provided sparse information on how to protect women from violence. Only two countries, India and Cambodia, had policies that stated that a counsellor should address potential risks of testing in a pretest session; however, neither policy identified violence as a specific risk. Only Guyana, Kenya and Papua New Guinea had policies in which violence was mentioned as a risk associated with HIV serostatus disclosure. Information in Guyana's policy alluded to violence in a sample referral sheet that includes 'Support for Domestic Violence Victims' among its many services listed. Kenya's policy stated that counselling on disclosure should take into consideration risks of violence and 'social instability'. Papua New Guinea's policy stressed that disclosure may not be appropriate for women who experience partner-based violence. South Africa's policy stated that the prevention of genderbased violence was one of its HIV prevention strategies. However, there was no other mention of violence against women in the testing policy. The issue of violence was not addressed in the rest of the policies.

\section{Obligation to fulfil}

We reviewed policies for evidence that governments were meeting their obligation to fulfil; that is, the policies helped to create an environment for the enjoyment of rights. Our analysis 
focussed on the provision of counselling services, access to treatment and plans for implementation.

Provision of counselling services-The provision of counselling services is one way in which the government can help to ensure that women receive information about their rights in regard to HIV testing and to ensure that women are afforded the opportunity to make an informed choice to test. Our policy analysis revealed a tendency across the countries to simplify the pretest counselling process. All the national policies indicated that clients should be given some information prior to testing, but they differed over what that information should be. The pregnancy-specific policies all indicated that counsellors should advise women about PMTCT. Most policies also indicated that clients should be advised of the benefits of testing, the nature of HIV/AIDS and how to prevent sexual transmission. Other information in some policies included the importance of retesting; descriptions of available services, including antiretroviral treatment (ARV) and family planning; and the importance of partner notification. As stated earlier, only the policies of India and Cambodia addressed the risks of testing, and only India's policy stated that clients should be told they can receive services even if they refuse testing.

We found that the policies included information about the changes in the way pretest counselling is conducted. The US policy was unique in its use of the term 'pretest information' instead of 'pretest counselling'. The new terminology may have been a reflection of the CDC's recent push to shorten the counselling requirements. Many of the policies stated that pretest counselling should be done in a group, rather than an individual session. Some of the policies that called for group counselling also indicated that, in certain situations, an individual session should be conducted. For example, Zambia's policy called for individual pretest counselling only for women who have additional questions or need clarification. Cambodia and Guyana, for example, allowed for group pretest information sessions but required some individual pretest counselling. However, Guyana's policy stated that individual counselling may be abbreviated but 'only if it is causing a barrier to testing itself'. Russia, Uzbekistan, Ukraine and Tanzania's policies indicated that pretest counselling should be offered individually and did not include any references to group counselling. In general, the role of pretest counselling was minimised in the testing policies and the groupcounselling approach was indicated for pregnant women in many of the settings.

All of the countries' policies regarding post-test counselling required individual sessions. When test results indicate a negative HIV status, the post-test counselling is designed to be brief with a focus on the importance of retesting later in the pregnancy and explanation of the 'window period' concept. When test results indicate a positive HIV status, the primary focus, as outlined in the policies, is on the administration of prophylaxis during pregnancy and postpartum to prevent HIV transmission to the infant. In some countries, post-test counselling also included information on infant formula to replace breastfeeding (when appropriate), testing of the infant and disclosure to spouses, partners and relatives. In Ukraine, where the HIV epidemic is fueled by injection drug use, the policy outlined the importance of referring the HIV-positive mother to drug abuse counselling services during the post-test counselling. 
Provision of treatment and care services-The provision of access to treatment and care services is another way that governments can ensure that HIV-positive pregnant women can enjoy their rights to health and wellbeing. Often, the countries made reference to their adherence to international or WHO standards in PMTCT programmes. Many of these descriptions included algorithms for the timing of testing and the process for administering medication. Most countries' policies stated that referrals should be made to treatment and care for those testing positive; Kenya, Uzbekistan and China were the exceptions.

The treatment and care available varied widely by country. The US policy, which contained a pregnancy-specific section, indicated that access to clinical care, prevention counselling and support services is essential. Some countries outlined that the mother and child are entitled to receive ARV after delivery; and this therapy is free in a number of countries. In addition to PMTCT and ARV therapy, the policies in Moldova and South Africa stated that HIV-positive mothers are eligible to receive free infant formula.

Plans for implementation of the policies-To ensure that the state is creating an environment that is conducive to women enjoying their rights, it was critical that governments have plans to implement and monitor the policies. While we were limited in our ability to assess how monitoring and evaluation plans were implemented, we were able to examine the plans for implementation as laid out in many of the countries' policies. The extent to which implementation was addressed in the policies on HIV testing of pregnant women varied greatly. The policies of China, Haiti and Uzbekistan did not provide any information on implementation of HIV testing and counselling. Other policies discussed one or two aspects of implementation, but the level of details varied greatly. For example, in Sudan, the policy stated that the purpose of the document was to provide healthcare providers with standards for delivery of the programme, but no other aspects of implementation were discussed. Finally, a number of other policies, such as those in South Africa and India, included extensive discussion on aspects of how the testing policies should be implemented.

The monitoring and evaluation plans, as outlined in the policies, focused primarily on increasing the uptake of testing, with limited attention paid to upholding women's rights during the process. Details about a country's proposed monitoring and evaluation strategy were present in seven of the policies reviewed. Most policies described the need for and use of a common set of indicators to collect data on programme implementation and the generation of reports based on these numbers. Some of the countries' policies called for keeping detailed records and statistics on the uptake of testing. The monitoring and evaluation information often focused on the collection of statistics on the uptake of testing, rather than the counselling process. In Russia, where women must sign an informed consent form outlining their understanding of their course of treatment and their responsibilities as patients receiving PMTCT, no documents were included in the policy regarding consent to testing. Ukraine's policy stated that healthcare providers complete lengthy forms and keep records on the different aspects of the counselling and testing process. The policy also requested that individuals who receive counselling and testing services complete feedback forms on their experiences. We recognise that the absence of a detailed implementation and monitoring plan within a national testing policy does not necessarily mean that the plan does 
not exist as part of a country's overall HIV testing and treatment strategy. More detailed plans may exist in other national guidance documents not included in our review.

\section{Discussion}

We identified several issues of concern in regard to states' obligations to respect, protect and fulfil through our review of recently adopted national policies for HIV testing of pregnant women. We found substantial gaps of information in the policies. These gaps are important to recognise and address in order to ensure that pregnant women's rights are upheld in the context of HIV testing during antenatal care. Based on this policy analysis, we offer several recommendations regarding further policy development and programmatic planning in regard to PMTCT and antenatal services.

The recent trend towards a shortened consent process raises concerns about whether clients' decisions to test will be sufficiently informed. We argue that more measures need to be taken to ensure that women's autonomy in the decision to test is upheld. While it is clear from the review of current HIV testing policies that countries have adopted a PITC model, there remain inconsistencies in the language used to define these models. Confusion in terminology raises concerns that once policies are implemented in clinics, the provider is left with room for interpretation of how to render testing and counselling services. We worry that this could lead to uninformed and even forced testing, especially if the provider has limited time and resources. A recent study in a Canadian antenatal care setting where PITC was the standard of care, $7 \%$ of the women believed either they were not tested or were not aware they were tested and were in fact tested for HIV during pregnancy (Guenter $e t$ al. 2003). Research is urgently needed in order to understand how policies with PITC for pregnant women are being implemented. Moreover, it is likely that HIV testing policies will influence demographically and ethnically diverse women differently. Thus, further research with a wide range of pregnant women (for example, ethnic and racial minorities, economically disadvantaged, varying educational and literacy levels, migrant and refugee populations and women accessing private versus public antenatal care centres) should be conducted. Pregnant women's ability to consent to HIV testing is called into question, especially in cases where there is not a protocol for what happens when a woman declines testing and in situations where newborns are tested when a mother's status is unknown. More information is needed to understand how providers ensure that informed consent is given, what providers do when women decline HIV testing during pregnancy, the consequences to the women for declining an HIV test and how these consequences are communicated to women.

We also found there to be a lack of detail in the policies on how confidentiality of HIV testing results will be protected in antenatal clinics. Confidentiality of test results of pregnant women may be jeopardised in these situations where multiple healthcare providers may feel that they are entitled to know the mother's status. Breach of confidentiality is also a risk in settings where special spaces are designated specifically for HIV-positive mothers.

Additionally, it may be problematic for a pregnant woman to keep her test results confidential from partners and family members who know she will be offered the HIV test results as part of antenatal care. The implications of disclosure may be especially 
troublesome and complex given what is known about women's fear of violence related to disclosure of HIV status.

We found there to be a lack of measures to ensure that women do not experience adverse consequences to being tested for HIV during pregnancy. De-emphasising the importance of pretest counselling in PITC models should be met with skepticism. To our knowledge, pretest 'information sessions' and group-counselling for pregnant women have not been thoroughly evaluated to ensure that women are ready to test. Counselling has the potential to be useful in helping to determine a woman's readiness to be tested for HIV, the expectations of learning one's status, identifying and addressing potential risks in learning a positive HIV serostatus and coming to a decision to test and/or disclose the results to her partner, healthcare providers and others (Sprague et al. 2011, Ujiji et al. 2011). Given what is known about women's fear of violence from disclosure of HIV status, it is especially problematic that governments do not more thoroughly address this issue in their HIV testing policies for pregnant women. Our review of policies showed that there is far greater emphasis on the medical benefits and little attention to the potential social risks of testing for women. By only presenting the benefits of testing, policies are denying women their right to informed decision-making. Given the potential risks associated with testing and the potential for adverse outcomes to a woman being tested for or diagnosed with HIV, policies need to be written to explicitly instruct providers of the necessity of full disclosure to women regarding the potential negative consequences of testing.

Details on the provision of counselling services and the provision of treatment and care services need to be strengthened in nearly every country's testing policy. Research indicates that HIV testing does not always mean follow-up treatment is received. For example, Manzi et al. (2005) reported high testing uptake (95\%) among women in rural Malawi; however, they found a high rate of loss to follow-up during PMTCT in their cohort. Only $45 \%$ of HIV-infected mothers and $34 \%$ of their babies received the necessary nevirapine (Manzi et al. 2005). These findings indicate that, while PITC may increase the rate of testing uptake, it does not necessarily positively influence rates of follow-up care.

We also noted a lack of details on the implementation of the HIV testing protocols, plans for monitoring and evaluation and plans for follow-up care for women who test positive for HIV. It is necessary to conduct on-going monitoring of testing programmes where the traditional pretest counselling is replaced with group sessions and pretest information sessions in order to more fully understand the adequacy of such models in allowing women to make informed decisions regarding an HIV test during pregnancy. Additionally, it is critical to ensure that antenatal clinics are staffed with trained counsellors to provide services to pregnant women who learn of their HIV positive serostatus as part of routine antenatal care. Lastly, implementation plans could include tools to help guide providers in how to counsel women about the potential social risks associated with HIV testing and diagnosis.

The policies included in this review have only recently been adopted. More time is needed to understand how these policies will be implemented. In addition, more operational research is needed to understand the impact of these policies in practice and the implications 
these policies have for pregnant women. Nonetheless, we argue that, at this time, it is important to consider these policies in terms of a human rights framework. It is through this lens that policies should be made to ensure that pregnant women can learn their HIV status under conditions that uphold their human rights and that programmes should be designed to promote the uptake of HIV testing to both prevent mother-to-child transmission and to provide HIV-positive women with longer-term services and care.

\section{Acknowledgments}

The concept for this article arose out of a project that was funded by the Open Society Institute.

\section{References}

Avert: International HIV and AIDS Charity. [Accessed 26 May 2012] HIV testing in pregnancy. 2012. [online]. Available from: http://www.avert.org/hiv-testing-pregnancy.htm

Bennett R. Routine antenatal HIV testing and informed consent: an unworkable marriage? Journal of Medical Ethics. 2007; 33(8):446-448. [PubMed: 17664300]

Burns K. Russia's HIV/AIDS epidemic: HIV/AIDS among women and problems of access to services. Problems of Post-Communism. 2007; 54(1):3-11.

Campbell T, Bernhardt S. Factors that contribute to women declining antenatal HIV testing. Health Care for Women International. 2003; 24(6):544-551. [PubMed: 12851173]

CDC (Centers for Disease Control and Prevention). Revised recommendations for HIV testing of adults, adolescents, and pregnant women in health-care settings. MMWR Recommendations and Reports. 2006; 55(RR-14):1-17. quiz CE1-4.

Csete J, Schleifer R, Cohen J. 'Opt-out' testing for HIV in Africa: a caution. Lancet. 2004; 363(9407): 493-494. [PubMed: 14962543]

DeCock KM. From exceptionalism to normalisation: a reappraisal of attitudes and practices around HIV testing. British Medical Journal. 1998; 316:290-293. [PubMed: 9472517]

de Paoli MM, Manongi R, Klepp KI. Factors influencing acceptability of voluntary counselling and HIV-testing among pregnant women in northern Tanzania. AIDS Care. 2004; 16(4):411-425. [PubMed: 15203410]

Fernandez MI, Wilson TE, Ethier KA, Walter EB, Gay CL, Moore J. Acceptance of HIV testing during prenatal care. Perinatal guidelines evaluation project. Public Health Reports. 2000; 115(5): 460-468. [PubMed: 11236018]

Galletly CL, Pinkerton SD, Petroll AE. CDC recommendations for opt-out testing and reactions to unanticipated HIV diagnoses. AIDS Patient Care and STDs. 2008; 22(3):189-193. [PubMed: 18290754]

Gielen AC, Fogarty L, O'Campo P, Anderson J, Keller J, Faden R. Women living with HIV: disclosure, violence, and social support. Journal of Urban Health. 2000; 77:480-491. [PubMed: 10976619]

Gruskin S, Ahmed S, Ferguson L. Provider-initiated HIV testing and counseling in health facilities what does this mean for the health and human rights of pregnant women? Developing World Bioethics. 2008; 8(1):23-32. [PubMed: 18315722]

Guenter D, Kaczorowski J, Carroll J, Sellors J. Prenatal HIV tests. Routine testing or informed choice? Canadian Family Physician; Medecin De Famille Canadien. 2003; 49:1334-1340.

Jones D. Understanding why women decline HIV testing. RCM Midwives: The Official Journal of the Royal College of Midwives. 2004; 7(8):344-347. [PubMed: 15736899]

Maman S, Mbwambo JK, Hogan NM, Kilonzo GP, Campbell JC, Weiss E, Sweat MD. HIV-positive women report more lifetime partner violence: findings from a voluntary counseling and testing clinic in Dar es Salaam, Tanzania. American Journal of Public Health. 2002; 92:1331-1337. [PubMed: 12144993] 
Manzi M, Zachariah R, Teck R, Buhendwa L, Kazima J, Bakali E, Firmenich P, Humblet P. High acceptability of voluntary counselling and HIV-testing but unacceptable loss to follow up in a prevention of mother-to-child HIV transmission programme in rural Malawi: scaling-up requires a different way of acting. Tropical Medicine \& International Health: TM \& IH. 2005; 10(12):12421250. [PubMed: 16359404]

Medley A, Garcia-Moreno C, McGill S, Maman S. Rates, barriers and outcomes of HIV serostatus disclosure among women in developing countries: implications for prevention of mother-to-child transmission programmes. Bulletin of the World Health Organization. 2004; 82(4):299-307. [PubMed: 15259260]

OHCHR (Office for the High Commissioner for Human Rights). International Human Rights Law. 2011. [online]. Available from: http://www.ohchr.org/en/professionalinterest/Pages/ InternationalLaw.aspx [Accessed 5 October 2011]

Peltzer K, Mosala T, Shisana O, Ngueko A, Mnggundaniso N. Barriers to prevention of HIV transmission from mother to child (PMTCT) in a resource poor setting in the Eastern Cape, South Africa. African Journal of Reproductive Health. 2007; 11(1):57-66. [PubMed: 17982948]

Pool R, Nyanzi S, Whitworth JA. Attitudes to voluntary counselling and testing for HIV among pregnant women in rural south-west Uganda. AIDS Care. 2001; 13(5):605-615. [PubMed: 11571007]

Rennie S, Behets F. Desperately seeking targets: the ethics of routine HIV testing in low-income countries. Bulletin of the World Health Organization. 2006; 84(1):52-57. [PubMed: 16501715]

Sprague C, Chersich MF, Black V. Health system weakness constrain access to PMTCT and maternal HIV services in South Africa: a qualitative enquiry. AIDS Research and Therapy. 2011; 8:10. [PubMed: 21371301]

Ujiji OA, Rubenson B, Ilako F, Marrone G, Wamalwa D, Wangalwa G, Ekstrom AM. Is ‘Opt-out HIV Testing' a real option among pregnant women in rural districts in Kenya? BMC Public Health. 2011; 11:151. [PubMed: 21385423]

UNAIDS/WHO. Policy statement on HIV testing. 2004. [online]. Available from: http:// www.who.int/rpc/research_ethics/hivtestingpolicy_en_pdf.pdf [Accessed 23 March 2011]

UNDP. A human rights-based approach to development programming in UNDP-adding the missing link. 2008. [online]. Available from: http://www.undp.org/governance/docs/ HR_Pub_Missinglink.pdf [Accessed 9 January 2008]

WHO and UNAIDS (World Health Organization and the Joint United Nations Programme on HIV/ AIDS). Guidance on provider-initiated testing and counseling in health facilities. 2007. [online]. Available from: http://whqlibdoc.who.int/publications/2007/9789241595568_eng.pdf

Yin PL, Shing KY, Hung TC. Maternal views and acceptance of antenatal HIV screening in a university teaching hospital in Kong Kong. The Journal of Reproductive Medicine. 2003; 48(12): 969-974. [PubMed: 14738025] 


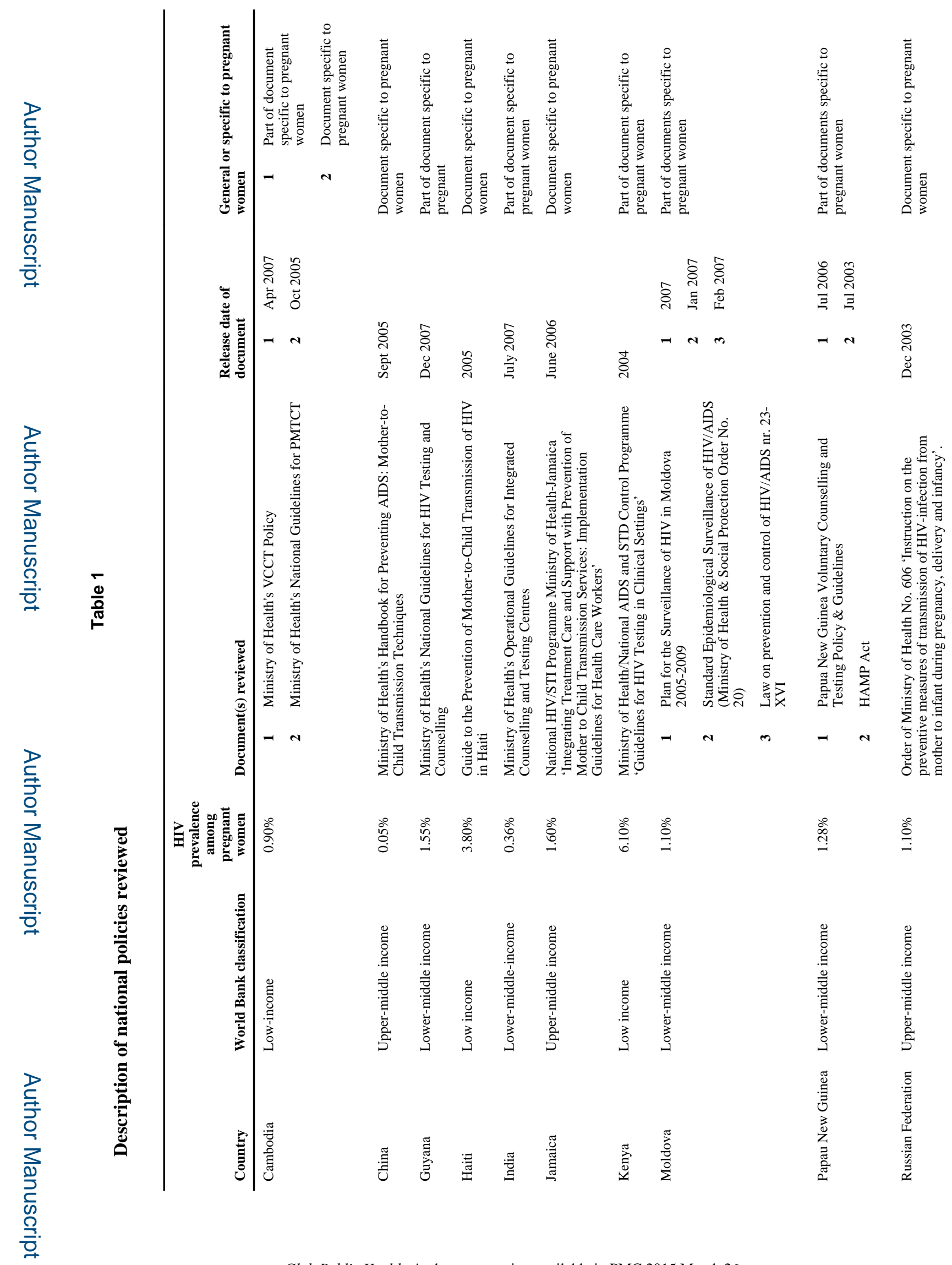

Glob Public Health. Author manuscript; available in PMC 2015 March 26. 


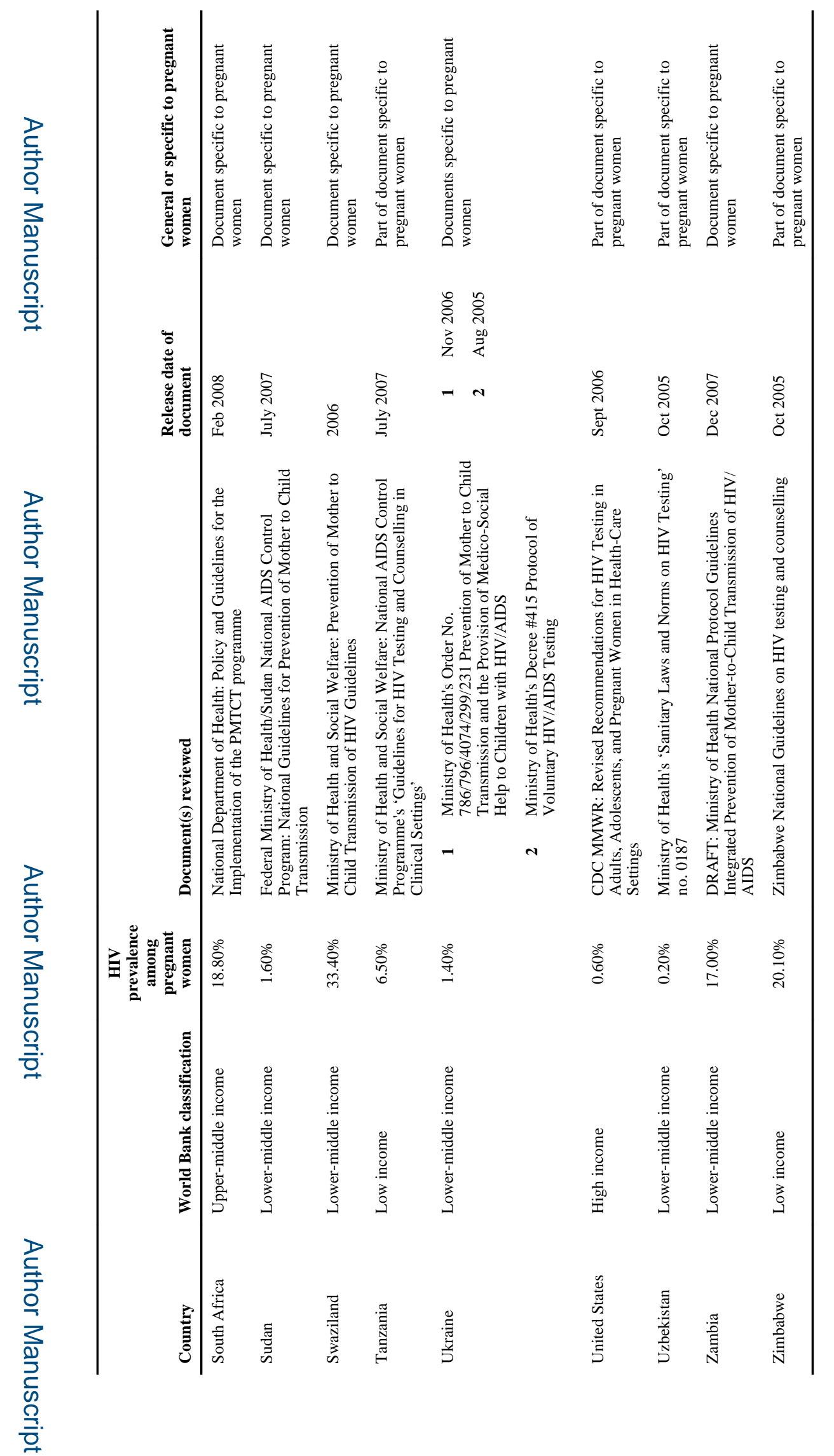

Glob Public Health. Author manuscript; available in PMC 2015 March 26. 
Table 2

\section{Human rights framework for analysing HIV testing policies}

\begin{tabular}{|c|c|}
\hline Government obligation & Components in framework for assessing HIV testing policies \\
\hline \multirow[t]{3}{*}{ Obligation to respect } & Opportunity to learn one's HIV status \\
\hline & - $\quad$ Right to decline HIV testing without penalty in the health care setting \\
\hline & - $\quad$ Assurance of confidentiality of testing results from third parties \\
\hline Obligation to protect & $\begin{array}{l}\text { Insurance of adequate measures to protect from potential adverse consequences of testing and/or } \\
\text { disclosing one's status (including: stigma, violence and coercion of women's reproductive choices) }\end{array}$ \\
\hline \multirow[t]{4}{*}{ Obligation to fulfil } & - $\quad$ Provision of counselling services \\
\hline & - $\quad$ Access to adequate PMTCT services and follow-up ARV therapy for herself and her child \\
\hline & - $\quad$ Access to necessary psychological and social support services \\
\hline & $\begin{array}{l}\text { - Plans for implementation in order to create a conducive environment for women to get tested, decline } \\
\text { testing, access treatment and care }\end{array}$ \\
\hline
\end{tabular}

